\title{
Student Learning Motivation and Psychological Hardiness: Interactive Effects on Students' Reactions to a Management Class
}

\author{
MICHAEL S. COLE \\ University of St. Gallen \\ HUBERT S. FEILD \\ STANLEY G. HARRIS \\ Auburn University
}

\begin{abstract}
We propose here that simultaneously considering the combined effects of students' learning motivation and psychological hardiness can increase understanding of the learning experience and its impact on important learning outcomes. Specifically, we hypothesized that the relationship between learning motivation and learning outcomes would be moderated by individuals' psychological hardiness. We collected data in two studies. The first established the psychometric properties of a newly developed scale, the second tested related research hypotheses. After controlling for socially desirable responding and dispositional learning orientations, our hypothesized interaction between participants' initial motivation to learn and their psychological hardiness explained differences in participants' postlearning motivation, depressive symptomatology, and reactions to their classroom experience assessed 2 months later. The study's findings have particular relevance for anyone who has ever taught or been involved in teaching. At times, for example, students can feel overwhelmed by the numerous responsibilities associated with being a college student. As a result, some will suffer a loss in motivation to perform and, even worse, a few will experience a severe state of depressed mood. Consequently, in this study we address these concerns and offer specific recommendations that could be implemented by universities and instructors to circumvent these detrimental outcomes.
\end{abstract}

Various conditions of stress and psychological strain can affect individuals' ability to be productive. Defined as any set of "circumstances that threaten or are perceived to threaten our wellbeing, and thereby tax our coping abilities" (Weiten, Lloyd, \& Lashley, 1991: 65), stress can have lasting effects on performance and cognitive functioning (Weiten et al., 1991). Across a series of stud-

The authors thank Roy Lewicki and the two anonymous reviewers for their helpful suggestions. A previous version of this manuscript was presented at the 2001 Academy of Management Conference in Washington, DC. ies, Fogarty, Machin, Albion, Sutherland, Lalor, and Revitt (1999) concluded that stress had strong, direct effects on individuals' strain and satisfaction. Furthermore, burnout resulting from psychological stress has been identified as a potential problem for all professions, including students (Weiten et al., 1991) and has been linked to depression, fatigue, and loss of motivation (Cordes \& Doughtery, 1993).

A growing literature suggests that, for many students, attending college is particularly stressful (e.g., Furr, Westefeld, McConnell, \& Jenkins, 2001; Swick, 1987; Zirkel \& Cantor, 1990). Over the course 
of an academic term, students must not only perform academically (e.g., complete term papers, class projects, exams, and meet parental expectations) but also take care of personal responsibilities (e.g., manage finances, hold part-time jobs) and their social needs (e.g., make and maintain friendships). Drawing on previous research, we reasonably assume that college students suffering from stress often experience disruptions in cognitive functioning that negatively affect their learning as well as their general outlook toward academic life (Macan, Shahani, Dipboye, \& Phillips, 1990). Zirkel and Cantor (1990), for instance, found students who were highly invested in academic achievement experienced higher levels of stress and reported more dissatisfaction during their years of college.

In addition to direct effects, the stresses and strains associated with the college experience may affect students' functioning through more indirect mechanisms. Numerous studies have empirically linked academic stress with students' depression (e.g., Dykman, 1998; Zirkel \& Cantor, 1990). For example, Brackney and Karabenick (1995) reported negative correlations between students' depression and their motivation to learn, time management, and effort. Similarly, in a recent survey conducted by Furr et al. (2001), more than half the students reported that their academic failures had caused a depressive episode. In sum, the college experience, and more specifically, the pressures of academic achievement and learning are stressful for many college students, and this stress may make achievement and learning more difficult.

As stress occurs in college students' everyday lives, it affects them in differing ways. As noted by Kobasa (1979), many persons leading highly stressful lives fail to show physiological or psychological symptoms of illness, while other high-stressed individuals report becoming physically and psychologically ill. Such findings have led many "stress-illness" researchers to shift their emphasis toward identifying "resistant resources" (Antonovsky, 1979) that shield some from the otherwise detrimental effects of stress. Accounting for the individual outcomes of stress requires considering both individual factors associated with inherited vulnerability and resistance (see, Maddi, 1999a). As stresses persist, strain reactions increase to the point at which physical (e.g., heart disease) and mental (e.g., depression, anxiety) illnesses become more likely. As to vulnerability factors, Maddi's model argues that as stresses continue to mount, strain reactions may increase to the point at which wellness breakdown (physical or mental) is likely to occur.
Wellness breakdown is less likely to occur when resistant factors are present to buffer against the adverse effects of stresses. Major resistant factors include exercise and nutrition, social support, and hardiness attitudes. In examining various combinations of these resistant factors, Kobasa, Maddi, Puccetti, and Zola (1985) reported synergistic effects among all three, with hardiness attitudes being the most effective buffer against illnesses. In an attempt to shed further light on the nature of resistant resources that insulate individuals from the negative impacts of stress, Gelso and Fassinger (1992) suggested future research more fully explore the psychological constructs, such as psychological hardiness, that comprise a healthy personality.

Our main objective here was to examine the role of psychological hardiness (Kobasa, 1979), in the context of university coursework. To our knowledge, this is the first study to consider the moderating role of college students' hardiness attitudes in the relationship between learning motivation and learning outcomes. We extend the literature by providing an overarching rationale as to why we predict hardiness will moderate the relationships between students' learning motivation and relevant criteria. If hardiness is found to moderate the relationship between students' motivation to learn and learning criteria, these results would suggest further additions to learning motivation's nomological net (see, e.g., Colquitt, LePine, \& Noe, 2000). Furthermore, hardiness may hold important practical implications for educators. For example, researchers have shown hardiness training positively increased individuals' hardiness attitudes and diminished individuals' subjective (e.g., depression) and objective (e.g., blood pressure) signs of strain (Maddi, 1987; Maddi, Kahn, \& Maddi, 1998).

Due to its relative absence from the learning and education literature, we first introduce the psychological hardiness construct and describe its underlying mechanisms. Next, we briefly review the motivation-to-learn literature to illustrate its robust relationship with learning outcomes. Given that academic achievement and learning are stressful events for many college students, we then describe how students' hardiness is expected to moderate the relationships between motivation to learn and several pertinent criteria, including postlearning motivation, depressive symptomatology, and students' reactions to the classroom and instructor.

\section{PSYCHOLOGICAL HARDINESS}

Psychological hardiness represents a single latent variable (Britt, Adler, \& Bartone, 2001), comprised of 
three obliquely related attitudes, that is, commitment, control, and challenge. Commitment is defined as a "tendency to involve oneself in (rather than experience alienation from) whatever one is doing or encounters" (Kobasa, Maddi, \& Kahn, 1982: 169). Control is described as a "tendency to feel and act as if one is influential (rather than helpless) in the face of the varied contingencies of life" (Kobasa et al., 1982: 169). Challenge is described as a "belief that change rather than stability is normal in life and that the anticipation of changes are interesting incentives to growth rather than threats to security" (Kobasa et al., 1982: 169).

The three interrelated hardiness attitudes of commitment, control, and challenge are thought to influence two underlying mechanisms that enhance the health and performance of persons experiencing stressful conditions (Maddi, 1999a). Specifically, hardy attitudes are believed to influence how individuals experience and cope with stressful life circumstances (e.g., Bartone, Ursano, Wright, \& Ingraham, 1989; Britt, Adler, \& Bartone, 2001; Florian, Mikulincer, \& Taubman, 1995; Maddi, 1999b; Maddi \& Hightower, 1999). In the perception and evaluation of stressful life events, Bartone et al. (1989) likened hardy persons to optimists who are apt to perceive challenges in a positive light. Therefore, hardy persons experience activities as interesting and enjoyable (i.e., commitment), as being a matter of personal choice (i.e., control), and as important stimuli for learning (i.e., challenge; Maddi, 1999b). Thus, the tendency to find positive meaning in life is a defining feature of hardiness (Kobasa, 1979; Maddi \& Kobasa, 1984). Furthermore, individuals exhibiting low hordiness sentiments have been found to display increased signs of depression (Rhonewalt \& Zone, 1989) as well as heightened anxiety and psychological distress (Rhonewalt \& Agustsdottir, 1984; Shepperd \& Kashoni, 1991).

The second underlying mechanism, hardy coping, involves the mental feat of putting each stressful circumstance "in a broader perspective so that it does not seem so terrible after all and finding a deeper understanding that reveals what needs to be done. This leads to taking decisive rather than avoidant actions to resolve the problem so that it no longer involves stress" (Maddi, 1999a: 68). For instance, Maddi and Kobasa (1984) noted high hardiness encourages persons to cope in a manner that transforms events into some less-stressful form for themselves. Furthermore, high hardiness involves the spinning of stressful events into opportunities for growth and development (Kobasa \& Puccetti, 1983). In ambiguous situations, hardiness equips individuals to draw upon a personal sense of commitment and control to find meaning in their tasks (Bartone et al., 1989) as well as exercise decision-making and goal-setting techniques (Kobasa \& Puccetti, 1983).

Over the past 20 years, the psychological hardiness construct has emerged as a buffer in the relationship between stressors and illness and has been shown to enhance performance, conduct, and morale (Maddi, 1999b). As part of a 12-year research program at Illinois Bell Telephone, the initial study of hordiness (Kobasa, 1979) found high-stressed, hardy individuals reported lower incidences of illness than high-stressed, nonhardy persons. While her first study could not identify causality, subsequent research by Kobasa and colleagues (Kobasa, Maddi, \& Courington, 1981; Kobasa, Maddi, \& Kahn, 1982) employed longitudinal data to test the relationship of hardiness to stressful life events. Consistent with the earlier findings, Kobasa et al.'s (1982) results from a 31/2-year longitudinal study provided evidence suggesting that when individuals are experiencing stressful life events, hardiness decreases the likelihood of detrimental effects associated with that stress. In the same study, the researchers also reported hardiness predicted both current and future well-being, even after controlling for prior illness. In a similar study, Wiebe and McCallum (1986) found individuals' hardiness scores were associated with later well-being. Additional studies have established comparable relationships across diverse samples, including lawyers and other nonexecutive groups (Kobasa, 1982).

Given evidence that psychological hardiness helps insulate individuals from the effects of stress and predicts future well-being, questions naturally arise regarding its generalizability across contexts and its influence on outcomes other than health. One might speculate, for example, that students who report having hardy attitudes will be more motivated to learn class material and more strongly committed to their classes than those reporting not having hardy attitudes. Preliminary evidence suggests support for this supposition. Sansone, Wiebe, and Morgan (1999), for instance, concluded that hardy persons were more likely to monitor and intentionally adjust their reactions when given the chance to prolong or avoid further exposure to an unpleasant experience (i.e., boring tasks). Hence, when individuals have control over their exposure to a stressor (e.g., attending class, studying for an exam), hardy individuals may be especially cognizant of the value of prolonging exposure. If they decide it is worth it, hordy individuals purposely engage in strategies to transform the activity into something perceived as more 
positive, that is, maintaining motivation to perform a worthwhile activity (e.g., Sansone et al., 1999; Sansone \& Harackiewicz, 1996).

\section{MOTIVATION TO LEARN}

Individual differences in ability and motivation to learn have long been considered important predictors of learning and training effectiveness (Campbell, 1989; Goldstein, 1993; Noe, 1986; Noe \& Schmitt, 1986). Learning motivation has been defined as the willingness to attend and learn material presented in a developmental program (e.g., Noe, 1986). Whereas ability accounts for what individuals can do, motivation to learn influences the decision-making processes determining the direction, focus, and level of effort individuals will apply to a learning activity (Noe, Wilk, Mullen, \& Wanek, 1997). For this reason many researchers have conceptualized and measured motivation to learn using a self-efficacy approach. These measures focus on individuals' self-perceptions of efficacy and are well suited for predicting how well individuals will perform (Mathieu \& Martineau, 1997).

Conceptualized as a malleable individual attitude, motivation to learn, suggest Noe and colleagues, influences trainees' decision-making processes, which ultimately impact the effectiveness of training and learning endeavors (Noe, 1986; Noe \& Schmitt, 1986; Noe et al., 1997). Furthermore, the positive relationship between motivation to learn and learning has been a robust one (e.g., Colquitt \& Simmering, 1998; Colquitt et al., 2000; Mathieu, Tannenbaum, \& Salas, 1992; Noe \& Schmitt, 1986).

Colquitt et al. (2000) meta-analyzed 106 learning motivation studies in an attempt to derive population values for individual and situational variables that are generally recognized as associated with training motivation. They found dispositional, attitudinal, and situational characteristics were all predictors of learning motivation. For the dispositional variables, anxiety was negatively related to all training variables and exhibited its strongest relationship with motivation to learn, suggesting the task of learning can be anxiety producing. When corrected for measurement error, anxiety's relationships with training motivation and posttraining self-efficacy were the strongest. Anxiety was also negatively related with several training outcomes, including declarative knowledge, skill acquisition, and reactions to training. Practitioners using an American Society of Training and Development survey that assessed trainees' anxiety and performance, found that $80 \%$ of 529 respondents reported having greater than nor- mal pretraining anxiety (Fisher, 1998). When trainers were asked their opinions of anxiety's impact on the trainees, $90 \%$ believed anxiety significantly interfered with trainees' ability to learn.

\section{INTERACTION EFFECTS OF HARDINESS AND LEARNING MOTIVATION}

Thus far, our focus has been on the independent effects of psychological hardiness and learning motivation on individuals' attitudes and wellbeing. In summary, the psychological orientations of college students are critical to their evaluations of their situations, which in turn, can impact their happiness, health, and attitudes toward academic achievement (Tomaka \& Blascovich, 1994). Empirical studies have shown, for instance, that college students' evaluations of situational demands play a role in forming academic expectations and perceptions of stress (Chemers, Hu, \& Garcia, 2001), as well as affective responses and physiological reactivity to those evaluations (Tomaka, Blascovich, Kelsey, \& Leitten, 1993; Tomaka, Blascovich, Kibler, \& Ernst, 1997). Furthermore, it is well established that individuals' learning motivation is associated with numerous learning outcomes, including postlearning motivation, satisfaction and reactions to the training, and anxiety (Colquitt et al., 2000).

However, beyond the value of main-effects models involving hardiness or motivated learning, an integrative model that encompasses their additive as well as interactive effects may offer a more powerful framework for predicting and understanding important outcomes. We propose that learning motivation and hardiness will interact to predict students' affective reactions. Although researchers have explored relationships between motivation to learn and affective learning outcomes (e.g., postlearning motivation, satisfaction with training) and hardiness and psychological well-being (e.g., depression), none have completed studies examining how students' hardiness may moderate the relationships between learning motivation and affective outcomes by influencing how students perceive and evaluate the academic demands placed upon them.

We predict the positive relationship between class-specific motivation to learn and affective outcomes will be strongest when hardiness is high. Under these circumstances, students will have higher academic expectations, in part, because they are motivated, feel efficacious, and perceive their world and their ability to cope with it as less threatening. Energized by the academic challenges, these students are expected to remain mo- 
tivated, be happier and less depressed, and react favorably toward their coursework and instructors. Conversely, we predict the positive relationships between learning motivation and affective outcomes to be weakest when students have low hardiness. Under these circumstances, students are likely to view their world in such a way that results in academic maladjustment, including decreased motivation and mental health, and they are likely to be more dissatisfied with their courses and instructors. The affective criteria we examine and specific hypotheses are described below.

\section{Post-Class Learning Motivation}

Because learning motivation is malleable and can change over time (Noe, 1986), one can expect that students' level of learning motivation may change over the course of the term. Specifically, students' motivations to learn might increase, decrease, or stay the same. As we have already noted, academic achievement and learning are oftentimes perceived as stressful events, and thus, these stresses may negatively influence students' learning motivation as the academic term progresses. When students' motivation is low or the academic environment is perceived as stressful, knowledge acquisition is likely to suffer.

Furthermore, if students evaluate these academic demands as a threat, and appropriate coping mechanisms are not in place, they are likely to experience a decrease in motivation and effort (Brackney \& Karabenick, 1995). When coping mechanisms associated with hardiness are in place, similar academic demands are more likely to be viewed as a challenge, and students' motivation to learn is not expected to be detrimentally affected (Kobasa \& Puccetti, 1983). Students' hardiness involves the ability to manage the stressors created in demanding situations by means of a more positive appraisal and use of available coping resources more efficiently, resulting in the inclination to perceive demanding situations as challenges rather than threats. Specifically, then, we hypothesize that the relationship between students' initial learning motivation and postlearning motivation is moderated by students' hardiness. The nature of this hypothesized interaction is such that:

Hypothesis 1: Initial learning motivation is positively related to postlearning motivation of students reporting high hardiness and less strongly related to postlearning motivation of students reporting low hardiness.

\section{Depressive Symptomatology}

Depression has been identified as one of the most common problems among college students. After surveying students enrolled at four universities, Furr and her associates (Furr et al., 2001) reported $53 \%$ of the respondents indicated that they had experienced what they would label as depression since beginning college, with grade problems, loneliness, and financial concerns as the most frequently cited causes. These findings mirror earlier survey results reported by Westefeld and Furr (1987). Consequently, it is believed that the typical college student encounters many of life's stressors recognized to trigger bouts of depression.

Conceptually, research on depressive phenomena generally approaches depression as a continuum, ranging from depressed mood (mild, episodic states) to depressive disorders (severe affective illness, even suicidal thoughts). Further, the differing approaches to depressive phenomena have all been included under the general label depression (Compas, Ey, \& Grant, 1993). Here, we are less interested in the diagnosis of depression as a chronic illness; rather, we center our focus on acute episodes of depressed emotional tone (and related symptoms) and their expected effect on students' academic successes. Compas has reported that depressed mood may occur in response to a variety of environmental stimuli and last for varying lengths of time ( 2 weeks and even longer; Compas et al., 1993).

Depressive episodes are associated with a variety of adverse consequences, including a diminished ability to adequately function in an academic environment (Diagnostic and Statistical Manual of Mental Disorders, 4th ed., or DSM-IV; American Psychiatric Association, 1994). College students experiencing depression reportedly suffer impaired cognitive functioning (Dobson \& Kendall, 1993), which includes a failure to complete complex academic tasks and deficits in short-term memory and information processing. Not only does depression interfere with students' ability to use learning strategies effectively, it also reduces students' motivation to learn (Brackney \& Karabenick, 1995). As a consequence of lower academic efficacy, students would be less motivated to perform tasks necessary for academic success. In a series of experiments, Cervone, Kopp, Schaumann, and Scott (1994) found college students who were induced into a state of negative mood formed performance standards that significantly exceeded the level of performance the students judged they could attain. The researchers concluded such "selfdefeating" cognitive patterns could have destruc- 
tive, enduring effects on cognition, motivation, and psychological well-being.

In summary, poor academic performance has been ranked first in contributing to depression among college students (Furr et al., 2001), and, in turn, depressed students are less capable of accomplishing academic tasks and managing the resources that promote effective learning, including the management of their time, and their motivation and effort expended on tasks (Brackney \& Karabenick, 1995). Experiencing depression as a college student can have enduring negative consequences (cf. Cervone et al., 1994) and, therefore, it is an important outcome variable included in the current research.

Dykman (1998) proposed a motivational-cognitive theory of depression and found empirical support for his model. Dykman's (1998) studies indicated that motivational factors are highly relevant to understanding depression. For example, when confronted with a stressful event, college students striving to learn and self-improve (labeled growth seeking) exhibited adaptive coping strategies and reported few depressive symptoms. In contrast, students striving to establish basic self-worth and competence (labeled validation seeking) coped with stressful events by disengaging and showed strong signs of depression (Dykman, 1998). Building off this line of research, we propose that students who are highly motivated to learn course content are likely to view academic challenges as growth opportunities and should be expected to exhibit few depressive symptoms (cf. Dykman, 1998). However, all college students are not equally motivated, and, therefore, less-motivated students are likely to view academic demands and the associated tasks of learning class material as stressful events. In Dykman's (1998) study, such students exhibited an increased chance of experiencing a depressive episode. Therefore, how students interpret the academic demands placed on them by the environment will impact their ability to cope with that environment (Lazorus \& Folkman, 1984).

Chemers et al. (2001) reported that confident and optimistic students viewed their worlds in ways that are more likely to result in successful adjustment. Individuals' optimism and positive expectations are associated with their use of problemfocused coping rather than withdrawal behavior (Scheier, Carver, \& Bridges, 2000). Optimistic thoughts are also related with psychological wellbeing in a broad variety of stressful situations (Scheier et al., 2000). Further, "hardy people" are more inclined to attach positive meaning and importance to their activities and are also less vul- nerable to the ill effects of stressful events (Kobasa et al., 1982).

Taken together, these studies provide the rationale for our hypothesis that hardy students' optimistic evaluations and coping mechanisms will interact with their learning motivation and take the form of fewer depressive symptoms at the end of the academic term. Because motivated, hardy students are energized by the challenges of college life, we expect them to be less depressed and better adjusted. Specifically, we hypothesize the interaction will take the following form:

Hypothesis 2: Initial learning motivation is negatively related to depressive symptomatology for students with high hardiness levels and less strongly related to depressive symptomatology for students with low hardiness levels.

\section{Classroom Experiences}

Pintrich and De Groot (1990) concluded that students who were motivated to learn the coursework (not just get good grades) and perceived that their school work was interesting and challenging were more engaged in trying to comprehend the material. Although Pintrich and De Groot could not address causality, their data suggested students who choose to become cognitively engaged are those who are interested in, satisfied with, and value the classroom tasks. Previous research also found students who were clear on their goals and student roles were more satisfied with their work (Macan et al., 1990).

Similarly, motivated and psychologically hardy students could be expected to evaluate their learning experiences more positively than other students (cf. Chemers et al., 2001). We predict these results because of the buffering role that hardiness plays during stressful situations and environments (Maddi \& Hightower, 1999; Westman, 1990). Students' hardiness should have considerable influence on their perceptions of existing academic demands and available resources that are at the core of challenge and threat evaluations. That is, hardy persons' optimism and ability to perceive challenges in a positive light should enable them to cope with any stressful academic events experienced and focus on the tasks at hand, for example, attending class, learning the material, completing term papers, taking exams, and so on, which all contribute to a more favorable classroom experience. Therefore, we offer the following hypothesis: Hypothesis 3: Initial learning motivation is positively related to students' reactions 
to the classroom experience, that is, class reactions and instructor evaluations, for students with high hardiness levels, and less strongly related to students' reactions who report low hardiness levels.

\section{DEVELOPMENT OF THE HARDINESS MEASURE}

When testing multifaceted constructs, including hardiness, most researchers have opted to use a total score approach, whereby the subcomponents are combined in a linear fashion (Carver, 1989; Hull, Lehn, \& Tedlie, 1991). However, the total score approach has been criticized because of the loss of information that is inherent when an outcome is predictable on the basis of the total score (Hull et al., 1991). Although a second approach does exist for testing multifaceted constructs, that is, the individual score approach, users have noted that it contains more serious problems including interpretive complexity, and on a statistical level, analyses using subcomponents multiplies the number of hypotheses created and, subsequently, increases the likelihood of capitalizing on chance (Hull et al., 1991). Previous researchers have reported using l- or 3-factor models of psychological hardiness (e.g., Bartone et al., 1989; Roth, Wiebe, Fillingim, \& Shay, 1989; Sansone et al., 1999; Shepperd \& Kashani, 1991). In order to negate criticisms that could have arisen from our treatment of hardiness as a 1- or 3-factor construct, we made no a priori decisions regarding our new measure's dimensionality, and, therefore, followed Hinkin's (1995, 1998) guidelines for developing psychometrically sound measures. Next, because no contextually specific measure of psychological hardiness relating to school events was found in the literature and due to concerns regarding the construct validity of hardiness (Funk \& Houston, 1987; Hull, Van Treuren, \& Virnelli, 1987), we examined the measure's construct validity prior to its application in the main study.

\section{Method}

\section{Participants and Procedures}

During the third week of the academic term, 603 students enrolled in a Principles of Management course at a large southeastern university were offered the opportunity to participate in research for extra course credit. An information sheet was provided to participants explaining: (a) participation involved completing a questionnaire at the end of the term, (b) participation was voluntary, and there were no consequences if they withdrew their responses at a later date, and (c) researcher contact information.

Seven weeks later, participating students completed a survey questionnaire after taking the course's last exam. A $2 \frac{1}{2} 2$-hour time period was allotted for the mandatory exam. The exam was expected to take less than 1 hour to complete, providing students plenty of time to complete the study questionnaire. At the beginning of the final exam, students were reminded that once they finished and turned in their exam, they could complete the research questionnaire if they wished. The timing of the data collection, that is, during final exams week, was particularly advantageous for purposes of this study because that week is generally regarded as the most stressful during the academic term (Macon et al., 1990). In an attempt to read assigned materials, meet paper and project deadlines, and complete final preparations for exams, many college students find finals week very stressful. A total of 348 (58\%) students completed the survey questionnaire; $58 \%$ were male, $91 \%$ were White, and approximately $97 \%$ were of junior or senior standing with on average age of 21.3 years $(\mathrm{S} D=1.5)$.

\section{School-Related Hardiness Measure}

We modified slightly 18 items (six items per subcomponent) of the original 45 items used to assess hardiness by Kobasa (1979) and Bartone et al. (1989). Modification of the hardiness items entailed changing the items to reflect hardiness sentiments related to school. For example, the item, "I really look forward to most things in life" was changed to "I really look forward to most things at school." Consequently, the terms hardiness and schoolrelated hardiness are used interchangeably hereon. All items were rated using a 6-point response scale ( 1 = strongly disagree; $6=$ strongly agree).

Based on Carver's (1989: 583) observations and our desire to develop a school-related measure of hardiness that (a) has the simplest factor constitution possible and (b) a minimum number of items that adequately top the domain of interest (Thurstone, 1947), we conducted an exploratory factor analysis of the 18 hardiness items using direct oblimin rotation. Direct oblimin was chosen because past research has shown the hardiness subscales to be moderately correlated (e.g., Florian et al., 1995; Maddi \& Hightower, 1999). Results revealed four factors with eigenvalues greater than one (see Appendix A for the items). Because we were interested in achieving Thurstone's (1947) rec- 
ommendations, only items loading $\geq .40$ on the first factor were retained; the remaining items were deleted from further anolyses. Eight items were identified that represented the global measure of school-related psychological hardiness; the factor accounted for $26 \%$ of the total variance. Items from all three subcomponents loaded on the first factor. Responses to these eight items were averaged to represent the construct. Coefficient alpha of the scale was .86.

\section{Criterion Variables}

Measures were selected for the purpose of examining the construct validity of the school-related hardiness measure. In addition to our schoolrelated hardiness, measures of positive and negative affect, somatic and psychological strain, goal orientations, motivation to learn, and class reaction measures were also included in the survey questionnaire. Unless otherwise noted, all measures used a 6-point Likert scale ( $1=$ strongly disagree; 6 = strongly agree). Descriptive statistics and internal consistency coefficients for these variables are reported in Table 1.

Positive affect is characterized as individuals' feelings of enthusiasm, activity, and attention (Watson, Clark, \& Tellegen, 1988). Staw, Sutton, and Pelled (1994) suggested positive affect influences individual outcomes such as increased task activity, persistence, and improved cognitive functioning. Conversely, negative affect is characterized typically as a general mood of distress and nervousness (Watson \& Clark, 1984). Tellegen (1985) asserted that low positive affect and high negative affect are the most notable attributes of depression and anxiety. In addition, new or unexpected events are likely to be perceived as threats rather than as opportunities for individuals with negative affect.

Using a 5-point Likert scale ( $1=$ very slightly or not at all; 5 = extremely), respondents indicated the extent to which they "have felt this way during the past week" to a list of 20 adjectives describing different feelings and emotions (PANAS; Watson et al., 1988) representing both positive and negative affect. Internal consistency estimates were .86 (positive affect) and .83 (negative affect), respectively.

Greller and Parsons' (1988) Psychosomatic Complaints Scale was also included to assess strain. Respondents used a 5-point rating scale ( 1 = rarely or never; $5=$ always) to indicate how often they had experienced 16 descriptors of somatic and psychological stress during the past 2 months. Representative stress descriptors include "nervous or tense," "lack of appetite," "depressed mood," and "trouble sleeping." The descriptor, "difficulty concentrating" was deleted from the scale because of low inter-item correlations. Greller and Parsons have provided evidence of the scale's unidimensionality and construct validity. Internal consistency for the scale in Greller and Parsons' study was .91, and here, alpha was .84 .

Research (Button, Mathieu, \& Zajac, 1996; Tannenbaum \& Yukl, 1992) has suggested goal orien-

TABLE 1

Descriptive Statistics and Zero-Order Correlations Among Study 1 Variables $(N=333)$

\begin{tabular}{|c|c|c|c|c|c|c|c|c|c|c|c|c|c|}
\hline Variables & $M$ & $S D$ & 1 & 2 & 3 & 4 & 5 & 6 & 7 & 8 & 9 & 10 & 11 \\
\hline $\begin{array}{l}\text { 1. Gender }(1=\text { male; } \\
2=\text { female })\end{array}$ & 1.4 & .50 & - & & & & & & & & & & \\
\hline 2. Age & 21.0 & 1.50 & -.24 & - & & & & & & & & & \\
\hline $\begin{array}{l}\text { 3. Race }(1=\text { African } \\
\text { American; } 2= \\
\text { Caucasian) }\end{array}$ & 2.0 & .44 & .05 & -.02 & - & & & & & & & & \\
\hline 4. Positive affectivity & 3.4 & .74 & .06 & .05 & .02 & $(.86)$ & & & & & & & \\
\hline $\begin{array}{l}\text { 5. Negative } \\
\text { affectivity }\end{array}$ & 2.1 & .72 & .04 & .10 & .04 & -.01 & (.83) & & & & & & \\
\hline 6. Strain & 34.0 & 8.20 & .15 & .03 & .06 & -.14 & .44 & (.84) & & & & & \\
\hline $\begin{array}{l}\text { 7. Performance goal } \\
\text { orientation }\end{array}$ & 4.8 & .60 & .18 & -.07 & -.02 & .04 & .05 & .11 & (.79) & & & & \\
\hline $\begin{array}{l}\text { 8. Learning goal } \\
\text { orientation }\end{array}$ & 4.7 & .56 & .05 & .10 & -.00 & .27 & .04 & -.02 & .43 & $(.80)$ & & & \\
\hline 9. Motivation to learn & 4.1 & .82 & .30 & -.02 & -.01 & .38 & -.10 & -.05 & .17 & .21 & (.75) & & \\
\hline 10. Class reaction & 4.4 & .95 & .17 & .05 & -.07 & .21 & -.09 & -.10 & .17 & .25 & .50 & (.92) & \\
\hline 11. School-hardiness & 3.8 & .73 & .08 & .11 & -.03 & .27 & -.08 & -.16 & .06 & .36 & .29 & .36 & (.86) \\
\hline
\end{tabular}

Note. All tests are two-tailed. Correlations greater than .11 are significant at the .05 level. Correlations greater than .13 are significant at the .01 level. Coefficient alphas are reported on the diagonal. 
tation may explain important workplace behaviors (e.g., training motivation). Individuals with a learning goal orientation are likely to believe that ability can be changed with effort and experience (e.g., Dweck \& Leggett, 1988). Individuals with a performance goal orientation are likely to believe ability is fixed and cannot be changed by effort and experience. Consequently, performance-oriented individuals may be more likely to display defensive behavior during training (Forr \& Middlebrooks, 1990) in order to maintain their perceptions of competence. Therefore, Button et al.'s (1996) 8-item goal orientation measures of learning orientation (alpha $=.79$ ) and performance orientation (alpha $=$ .80) were included.

Past research has found robust relationships between training motivation and training outcomes such as learning (e.g., Baldwin, Magjuka, \& Loher, 1991; Martocchio \& Webster, 1992; Mathieu, Tannenbaum, \& Salas, 1992) and transfer of training (e.g., Colquitt et al., 2000). Four items were adapted from Noe and Schmitt (1986) to measure motivation to learn (alpha $=.75$ ).

A positive reaction to learning or training situation is important because satisfaction might have substantial influence on other training outcomes such as attendance and performance (Alliger, Tannenbaum, Bennett, Traver, \& Shotland, 1997). In order to assess students' reaction to the class experience, we used Wexley and Baldwin's (1986) 5 -item measure to assess class reaction. Coefficient alpha for the scale was .92.

\section{RESULTS}

As evidence of the newly developed school-hardiness measure's construct validity, we examined correlations between students' school-hardiness and their affective outcomes. We anticipated the school-hardiness measure to relate in specific, meaningful ways with the criterion variables. Specifically, hardiness was expected to exhibit positive relationships with students' positive affectivity, learning goal orientation, motivation to learn, and their reactions to the class. In addition, hardiness was also predicted to demonstrate negative relationships with students' negative affectivity, performance goal orientation, and strain.

As shown in Table 1, students' gender, age, and race were not associated with students' schoolrelated hardiness. As expected, school-related hardiness sentiments were positively related to the state variable, positive affectivity $(r=.27, p<.01)$ and two of the three learning variables, that is, learning goal orientation $(r=.36, p<.01)$ and motivation to learn $(r=.29, p<.01)$. With regard to classroom reactions, school-related hardiness was related to reactions to the class $(r=.36, p<.01)$. In addition, school-related hardiness also exhibited a negative association with strain, $(r=-.16, p<.01)$.

Results of the pilot study provided construct validity evidence for the school-related hardiness measure. The results suggested that students who were committed, were in control of their academic life, and enjoyed the challenges of school, that is, hardy students, were: (a) affectively more positive and had less psychosomatic complaints, (b) more motivated and enjoyed learning new things, and (c) provided a more favorable critique of their overall classroom experience.

\section{STUDY 2: PRIMARY STUDY}

\section{Method}

Having demonstrated the reliability and validity of the school-related hardiness measure, data were collected from a second sample. Based on our previous literature review, the focus of the second and primary study involved testing our hypotheses that psychological hardiness will moderate the relationships among learning motivation and affective outcomes.

\section{Participants and Procedures}

We conducted the second study over 8 weeks of a 10 -week academic term. During the second full week of class, students $(N=356)$ enrolled in an introductory Principles of Management course at a large, southeastern university were given the opportunity to participate in the study for extra course credit. The study protocol was similar to that of our pilot study, with the exception that an initial survey was administered at the beginning of the academic term. Therefore, to receive the extra-credit, participants were told that they must complete two surveys, one administered at the beginning of the term and the second, 8 weeks later at the end of the term. To ensure anonymity, participants were asked to write a 5-digit code that was easily remembered on each of the two completed questionnaires. This 5-digit code was used to match the two completed questionnaires.

Time 1 measure. The purpose of the Time 1 questionnaire was to collect data on participants' school-related hardiness and learning motivation. Graduate teaching assistants administered this part of the study during a regular class period. Of the 285 ( $80 \%$ response rate) who chose to participate and complete the first survey questionnaire (Survey 1), 59\% were male, 91\% were White, and 
approximately $98 \%$ were of junior or senior standing with an average age of approximately 22 years $(\mathrm{S} D=2.7)$.

Time 2 measure. Two months later at the end of the term, a second questionnaire (Survey 2) was administered by graduate teaching assistants to the student participants who had previously completed the first survey. As in the pilot study, Survey 2 was administered during final exam week in order to capture students' attitudes and reactions at a highly stressful time. In our discussion with students, we were told this period of time is often very stressful for students and we believed it to be an opportune time to collect the criterion data. During this final week, most students were dealing with a wide variety of stressful academic activities, such as studying for multiple final exams, completing research papers, making oral class presentations, and so forth.

The purpose of the Time 2 questionnaire was to collect the criterion data (see below for a complete discussion of criteria) and a second assessment of participants' school-related hardiness. Because anonymity was guaranteed, participants listed on Survey 2 the same 5-digit code they listed on Survey 1 . Of the original 285 who responded to Survey 1, we were able to match responses on Survey 2 for $156(55 \%)$ students for an overall participation rate of roughly $44 \%$. The sample on which the Time 2 data were based was 57\% male, 93\% White, and approximately $98 \%$ were of junior or senior standing. Average age of the participants was 22 years $(\mathrm{SD}=2.7)$. Tests between the participant samples in the Time 1 and 2 questionnaire administrations showed there were no demographic differences between the participant groups.

\section{Measures}

Unless otherwise noted, we used a 6-point Likertresponse format to measure attitudinal variables ( 1 = strongly disagree; 6 = strongly agree). To minimize artificial inflation of correlations between independent and dependent variables, we followed Podsakoff and Organ's (1986: 542) recommendations by ( $\alpha$ ), eliminating obvious item overlap on the independent and criterion measures and (b), collecting the dependent variables 2 months after collecting the independent variables.

\section{Learning Motivation}

Survey l, given during the second week of the quarter, included a measure of students' learning motivation. Four items were adapted from Noe and Schmitt (1986) to measure motivation to learn. Ex- ample items include "I will try to learn as much as I can of this material" and "I will exert considerable effort in learning this material." Internal consistency for the learning motivation scale was .85 .

\section{Psychological Hardiness}

Also incorporated in Survey 1 was the 18-item school-related hardiness measure developed in the pilot study. We performed a confirmatory factor analysis with the new data to test the unidimensionality of our measure. The eight items that previously loaded on factor one in the exploratory factor analysis were constrained to a single latent factor. Results indicated the single factor fit the data very well, $\chi^{2} / d f(79.37 / 20)=3.97, p<.01$; comparative fit index (CFI) = .94; goodness of fit index $(\mathrm{GFI})=.93$; and nonnormative fit index (NNFI) $=$ .92. Based on these results, we created a composite hardiness score by averaging participants' responses to the eight items; coefficient alpha for the 8-item scale was .86. In addition, we assessed the test-retest reliability of the school-related hardiness measure. After 2 months, the test-retest reliability coefficient was .71, indicating schoolrelated hardiness sentiments were reasonably stable over the 8-week interval.

Although the previous results suggested the new hardiness measure is unidimensional, that our 8-item hardiness measure is associated with the general construct or its subcomponents remains to be shown. Therefore, we examined the correlation between the 8- and 18-item composite measures and, then, correlations among the composite measures and hardiness' three subcomponents. Results showed the 8- and 18-item measures were strongly correlated $(r=.89)$. Moreover, correcting for attenuation in the measures, the relationship between the two measures was 1.0. Next, we inspected the relationships between the 8- and 18item composite measures and the three subcomponents; all were significant at the .001 level. The average correlation between our 8-item measure and the three subcomponents was .73, compared to .81 for the 18-item composite measure and the three subcomponents. In sum, these findings suggested our short, 8-item measure of school-related hardiness adequately taps both the general construct and each of its three subcomponents.

At the end of the academic term ( 8 weeks after administration of Survey 1), students completed a second survey. Included in Survey 2 were various measures of learning attitudes, psychological well-being, and measures developed to assess reactions to the class and instructors. 


\section{Motivation to Learn (Time 2)}

The identical four items (Noe \& Schmitt, 1986) used to assess students' motivation to learn at Time 1 were also used in the Time 2 questionnaire. Coefficient alpha of the measure was .82 .

\section{Depressive Symptomatology}

We selected Costa and McCrae's (1992) 8-item depression scale that represents one of six Big Five neuroticism facets. This facet scale assesses individuals' tendencies to experience depressive affect. High scorers are prone to feelings of sadness and guilt and are easily discouraged (Costa \& McCrae, 1992: 16). Further, Costa and McCrae reported convergent validity for the facet scale indicating correlations with five alternative measures of similar constructs (p. 47). Example scale items are "Sometimes things look pretty bleak and hopeless to me" and "Sometimes I feel completely worthless." Coefficient alpha of this measure was .75.

\section{Reaction to the Class}

As noted by Alliger et al. (1997), positive reactions to a learning or training situation are important because satisfaction might have substantial influence on other training outcomes such as attendance, performance, or "word-of-mouth" advertising that might impact future participants. In order to measure students' reaction to the class experience, we used Wexley and Baldwin's (1986) 5-item measure to assess class reaction. Example items are, "I feel more competent in the use of management skills and techniques" and "I would recommend this class to other students." Coefficient alpha for the scale was .90 .

\section{Instructor Evaluations}

The Principles of Management class was teamtaught by three professors. Students were asked to evaluate each professor on their knowledge, communication skill, preparedness, and class satisfaction. Example items are "[Name of professor] knew what he was talking about in the Principles of Management class," "[Name of professor] was prepared for each class session," and "I would take another class taught by [name of professor]." Students were assured their responses would remain anonymous and would never be shown to the professors. An index was created by averaging the ratings for the three professors (alpha $=.78$ ).

\section{Control Variables}

Various types of control variables were also included in the first questionnaire. Demographic characteristics (i.e., student classification, age, race, and gender) were controlled in all analyses.

Second, 10 items from the self-deception subscale of the Balanced Inventory of Desirable Responding (BIDR; Paulhus, 1991) were employed to control for any biases due to positive judgments of self-image. Recently, however, researchers have suggested socially desirable responding is not a response bias that should be a cause of concern (Krosnick, 1999; Ones, Viswesvaran, \& Reiss, 1996). Despite the recent literature, we included a measure of desirable responding because of the sensitive nature of many of our criteria (e.g., depressive symptoms, instructor evaluations). A sample item is "I always know why I like things" (coefficient alpha $=.71$ ).

Button et al. have suggested that certain situations, such as academic settings, may sensitize respondents to the value of learning and performance outcomes (Button et al., 1996). By definition, learning-oriented individuals should be motivated to learn (e.g., Farr \& Middlebrooks, 1990) and should have positive attitudes about situations in which they will learn and develop new skills (e.g., training). Consistent with this definition, Colquitt and Simmering (1998) found that learning orientation was positively related to motivation to learn. In contrast, individuals with a performance goal orientation are likely to presume ability is stable and unchanging. Therefore, these individuals are more concerned with displaying current abilities rather than developing new ones and may even avoid situations where their competence could be questioned (e.g., VandeWalle, 1997).

Based on this stream of research, we controlled for respondents' dispositional learning and performance goal orientations using Button et al.'s (1996) 8-item goal orientation measures. Similar to the method used by Colquitt and Simmering (1998), we included the scales at the initial (Survey l) and end point (Survey 2) of the study. Coefficient alpha's were computed by treating each scale score as one item in a 2-item scale (Colquitt \& Simmering, 1998). Coefficient alpha for the dispositional measures for learning orientation was .76, and performance orientation was .75 .

\section{Data Analyses}

To test our hypotheses, hierarchical moderated regression analysis was used so the order in which the predictor variables were introduced into the 
equation could be specified. The advantage in using hierarchical regression is that it allows us to define causal priority, remove spurious relationships, and determine incremental validity (Cohen \& Cohen, 1983). In our models, control variables were entered into the first three steps: demographic variables in Step 1, self-deception in Step 2 , and goal orientations in Step 3. At the fourth hierarchical step, the main effects of learning motivation and school-related hardiness were entered, and the two-way cross-product term was entered in the last step. This raises the question of multicollinearity, which makes the regression coefficients unstable and difficult to interpret (Cohen \& Cohen, 1983). To control for multicollinearity in the interaction terms, we followed Aiken and West's (1991) deviation score procedure.

The process involves transforming the data into deviation score form by centering predictor and moderator variables, and then rerunning each of the hierarchical regression models. After centering all variables, the variance inflation factor scores (VIFs) indicated no instances of multicollinearity among any of the variables or interaction terms.

When examining the regression results, any statistically significant $(p<.05)$ increase in $\Delta R^{2}$ involving the hypothesized relationships would indicate the variable entered in that step explains significant incremental variance in the criterion, above and beyond that accounted for by the variables entered in previous steps (Cohen \& Cohen, 1983). Hence, a significant $\Delta R^{2}$ in Step 5 would indicate the two-way interaction accounts for unique variance in the criterion.
For any significant interaction terms, we made graphic plots to gain a better understanding of the Learning Motivation $\times$ Psychological Hardiness interaction effects on the dependent variables (Cohen \& Cohen, 1983). Plots were made at one standard deviation above and below the mean for learning motivation (Time 1) and school-related psychological hardiness. In addition, based on plots, students' Time 1 learning motivation and hardiness scores were used to classify students into four groups (i.e., high learning motivation/ high hardiness, high learning motivation/low hardiness, low learning motivation/high hardiness, and low learning motivation/low hardiness) and ANOVAs were used to test for significant differences, followed by Tukey's Honestly Significant Differences (HSD) tests.

\section{RESULTS}

Table 2 contains the descriptive statistics, zeroorder correlations, and internal consistency estimates for the study variables. In general, the correlations were low to moderate and in expected directions.

Although not hypothesized, predictor variables' main effects were investigated by examining the correlations among the predictors and criteria (see Table 2). Both predictor variables, that is, learning motivation (Time l) and hardiness, were related with all study criteria in the expected direction. Learning motivation (Time 1) shared only $38 \%$ of the variance with students' postlearning motivation $(r=.62, p<.001)$. This is nearly identical to the

TABLE 2

Descriptive Statistics and Zero-Order Correlations Among Study 2 Variables $(N=150)$

\begin{tabular}{|c|c|c|c|c|c|c|c|c|c|c|c|c|c|c|c|}
\hline Variable & $M$ & $S D$ & 1 & 2 & 3 & 4 & 5 & 6 & 7 & 8 & 9 & 10 & 11 & 12 & 13 \\
\hline \multicolumn{16}{|l|}{ Controls: } \\
\hline 1. Gender $(1=$ male; $2=$ female $)$ & 1.4 & .50 & - & & & & & & & & & & & & \\
\hline 3. Race & 2.0 & .28 & .09 & .03 & - & & & & & & & & & & \\
\hline 4. Classification & 3.5 & .54 & .07 & .20 & -.04 & - & & & & & & & & & \\
\hline 5. Self-deception & 3.5 & .61 & -.11 & .11 & -.21 & .02 & $(.71)$ & & & & & & & & \\
\hline \multicolumn{16}{|l|}{ Predictors: } \\
\hline 8. Learning motivation (Time 1) & 4.3 & .80 & .02 & .06 & -.11 & -.10 & .08 & .41 & 27 & $(.85)$ & & & & & \\
\hline 9. Psychological hardiness & 3.8 & .80 & .07 & .28 & -15 & .18 & .32 & .48 & .17 & .26 & $(.86)$ & & & & \\
\hline \multicolumn{16}{|l|}{ Criteria: } \\
\hline 10. Learning motivation (Time 2) & 4.3 & .82 & .17 & .05 & -.04 & -.20 & .13 & .41 & .38 & .62 & .28 & $(.82)$ & & & \\
\hline 11. Depression & 3.0 & .72 & -.09 & -.04 & .26 & -.08 & -.36 & -.34 & -.05 & -.17 & -.22 & -.14 & $(.75)$ & & \\
\hline
\end{tabular}

Note. Decimals are omitted from correlations. For correlations of .16 or greater, $p<.05$. All tests are two-tailed. Coefficient alphas are shown on the diagonal for all multi-item measures. 
pre-post learning motivation correlation $(r=.65)$ reported by Colquitt and Simmering (1998). In addition, learning motivation was negatively related with depression $(r=-.17, p<.05)$ but positively related with class reactions $(r=.41, p<.001)$ and evaluation of the instructors $(r=.26, p<.001)$. Similar results were obtained between hardiness and study criteria. Hardiness was negatively related with students' depression $(r=-.22, p<.01)$ and positively related with postlearning motivation $(r=.28, p<.001)$, classroom reactions $(r=.28$, $p<.001)$, and instructor evaluations $(r=.31$, $p<.001)$.

Hypothesis 1 predicted that school-related hardiness would moderate the relationship between learning motivation assessed at Time 1 and postlearning motivation measured at the end of the academic term. As reported in Table 3, the two-way interaction term accounted for incremental variance in learning motivation (assessed at Time 2) $\left(\Delta R^{2}=.02 ; p<.05\right)$. As shown in Figure 1, initial motivation interacted with hardiness such that the positive relationship between initial and final motivation was amplified as hardiness increased (see Figure 1). Tukey's HSD post hoc comparisons ( $p<$ .01) indicated motivated/hardy students reported being more motivated to learn at the end of the term when compared to either group of students who lacked motivation at the onset of the academic term. Furthermore, as one might expect, motivated/nonhardy students also reported being more motivated at the end of the term compared to unmotivated/hardy $(p<.05)$ and unmotivated/nonhardy $(p<.01)$ students. Thus, Hypothesis 1 was supported.

Hypothesis 2 predicted the interaction of learning motivation (Time 1) and school-related hardiness would account for incremental variance in students' depressive symptomatology. Specifically, we expected initial learning motivation to be negatively related to depressive symptomatology for students with high hardiness levels and less strongly related to depressive symptomatology for students with low hardiness levels. When entered

TABLE 3

Summary of Moderated Hierarchical Multiple Regression Analyses ( $N=149-151)$

\begin{tabular}{|c|c|c|c|c|}
\hline \multirow[b]{3}{*}{ Variable Entry Order } & \multicolumn{4}{|c|}{ Criterion Variables } \\
\hline & $\begin{array}{c}\text { Learning } \\
\text { motivation (Time 2) }\end{array}$ & Depression & $\begin{array}{l}\text { Class } \\
\text { reaction }\end{array}$ & $\begin{array}{l}\text { Instructor } \\
\text { evaluations }\end{array}$ \\
\hline & $\boldsymbol{\beta}$ & $\boldsymbol{\beta}$ & $\boldsymbol{\beta}$ & $\boldsymbol{\beta}$ \\
\hline \multicolumn{5}{|l|}{ Step 1: Demographics } \\
\hline Age (years) & $-.13^{*}$ & .14 & -.09 & .09 \\
\hline Race & -.10 & $.27^{\star \star \star}$ & -.12 & -.05 \\
\hline Classification & $-.14^{*}$ & $-.15^{*}$ & $-.18^{* *}$ & -.10 \\
\hline$\Delta R^{2}$ after Step l & .03 & $.08^{*}$ & .04 & .04 \\
\hline \multicolumn{5}{|l|}{ Step 2: Response control } \\
\hline Self-deception & -.02 & $-.30^{\star * *}$ & $-.24^{\star \star *}$ & -.15 \\
\hline$\Delta R^{2}$ after Step 3 & $.24^{\star \star *}$ & $.05^{\star *}$ & $.26^{\star \star *}$ & $.14^{\star \star \star}$ \\
\hline \multicolumn{5}{|l|}{ Step 4: Main effects } \\
\hline Learning motivation (Time 1) & $.52^{\star \star \star}$ & -.11 & $.25^{\star \star *}$ & .10 \\
\hline Psychological hardiness & .08 & -.01 & $.18^{*}$ & $.22^{*}$ \\
\hline$\Delta R^{2}$ after Step 4 & $.22^{\star \star \star}$ & .01 & $.07^{\star \star \star}$ & $.05^{\star}$ \\
\hline \multicolumn{5}{|l|}{ Step 5: Two-way interaction } \\
\hline $\mathrm{LM} \times \mathrm{PH}$ & $.13^{*}$ & $-.20^{\star *}$ & $.20^{\star *}$ & .00 \\
\hline$\Delta R^{2}$ after Step 5 & $.02^{*}$ & $.04^{* *}$ & $.04^{* *}$ & .00 \\
\hline Overall $F$ & $15.0^{\star \star \star}$ & $6.2^{\star \star \star}$ & $10.0^{* * *}$ & $3.9^{* * *}$ \\
\hline Overall $R^{2}$ & .52 & .31 & .41 & .22 \\
\hline
\end{tabular}

Note. Only final model results are reported. $\beta$ is the standardized regression coefficient. All tests are two-tailed.

${ }^{\star} p<.05 .{ }^{* *} p<.01 .{ }^{* \star *} p<.001$. 


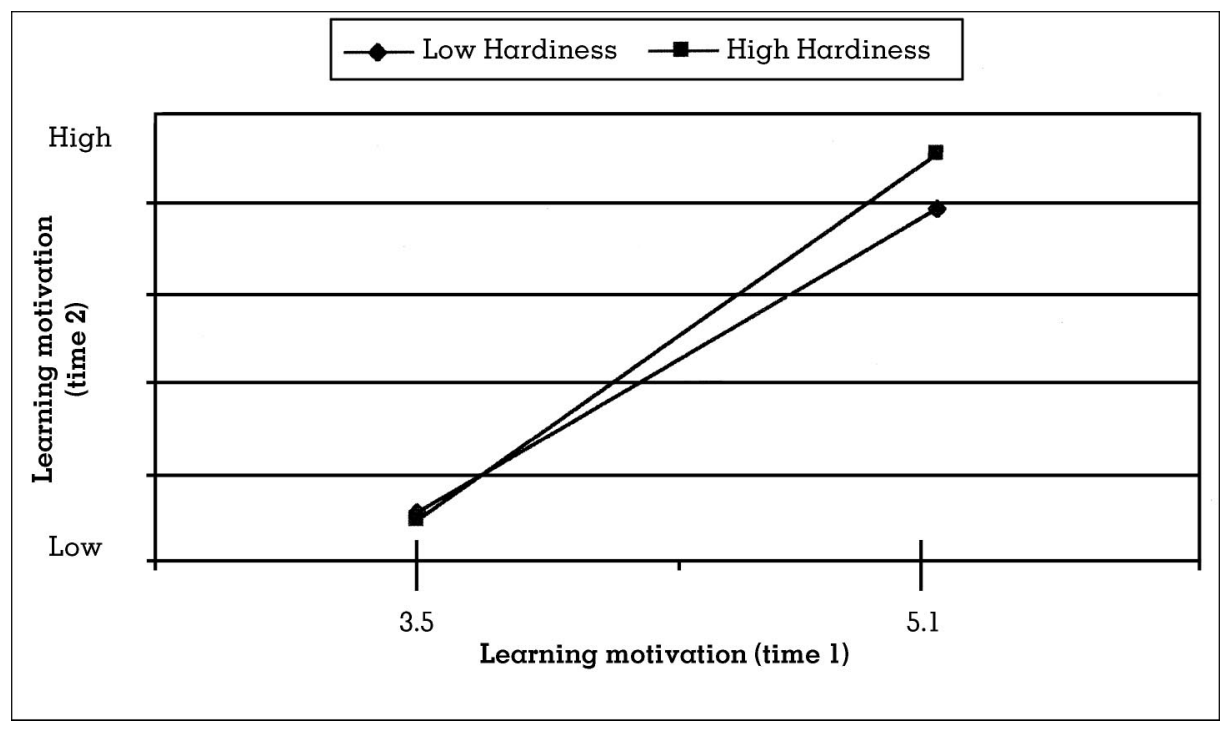

FIGURE 1

Learning motivation (Time 2) predicted by the two-way interaction between learning motivation (Time 1) and school-related psychological hardiness at low and high levels of hardiness. The numbers 3.5 and 5.1 are one standard deviation above and below the mean (4.3) for the learning motivation

(Time 1) scale.

in the final step, the interaction term incrementally accounted for $4 \%$ of the variance in depressive symptoms $\left(\Delta R^{2}=.04 ; p<.01\right)$. As hypothesized and shown in Figure 2, the relationship between initial learning motivation and depressive symptomatology was markedly more negative for students such that motivated/hardy students exhibited the lowest depressive symptomatology. Unexpectedly, however, Figure 2 also shows a slight positive relationship between learning motivation and depression for those students low in hardiness and also shows unmotivated/hardy students were slightly more depressed than unmotivated/nonhardy students. However, Tukey's HSD post hoc comparisons indicated there were no differences among the student groups. Therefore, Hypothesis 2 was only partially supported and revealed relationships somewhat more complex than originally hypothesized.

Hypothesis 3 predicted that the positive relationship between initial learning motivation and stu-

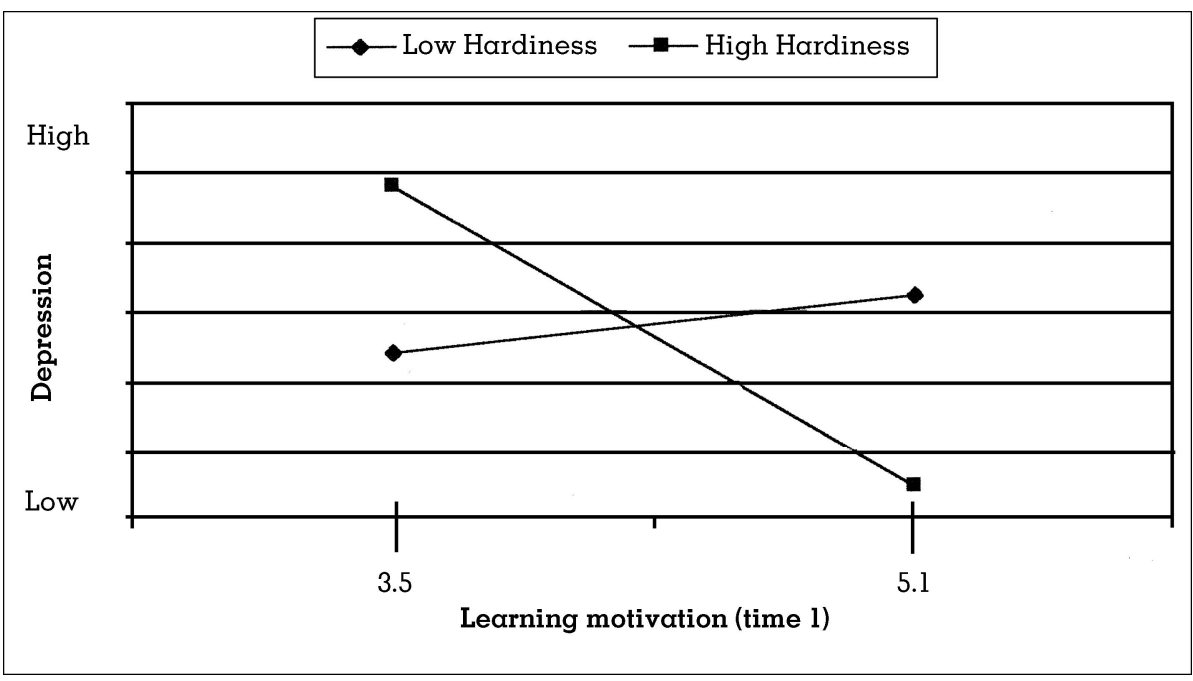

FIGURE 2

Depression predicted by the two-way interaction between learning motivation (Time 1) and schoolrelated psychological hardiness at low and high levels of hardiness. The numbers 3.5 and 5.1 are one standard deviation above and below the mean (4.3) for the learning motivation (Time 1) scale. 
dents' reactions to the classroom experience and evaluations of their professors would be magnified by hordiness. Consistent with this hypothesis, when students' class reactions were regressed on the Learning Motivation $\times$ Hardiness cross-product, the moderated regression results indicated the interaction term explained unique variance $\left(\Delta R^{2}=\right.$ .04; $p<.01$ ). Tukey's HSD post hoc comparisons indicated motivated/hardy students reported a more positive experience $(p<.01)$ compared to all other student groups. Contrary to our expectations, the learning motivation/hardiness interaction did not account for unique differences in students' evaluations of the professors $\left(\Delta R^{2}=.00 ; n s\right)$. We also ran post hoc regression analyses with the three individual professor evaluations regressed on the same set of predictor variables. Again, in each of the regression models, all were nonsignificant. All regression results are summarized in Table 3. Thus, of the two criteria tested in Hypothesis 3 , only students' class reactions received empirical support.

Figure 3 shows the interaction between learning motivation and hardiness on students' reactions to the class. As previously mentioned, motivated/ hardy students reported the highest overall experience and unmotivated/nonhardy students reported the poorest overall experience in the class. Both, motivated/nonhardy and unmotivated/hardy students judged their classroom experiences similarly.

Beyond statistical significance, these results presented for Hypotheses 1-3 also have practical importance. To quantify practical significance, we calculated binomial effects size displays (BESD: Rosenthal, 1991; Rosenthal \& Rosnow, 1984; Rosnow \& Rosenthal, 1996). This procedure involves placing the criterion into dichotomous terms, such as "motivated" or "unmotivated" and "depressed" or "not depressed" using median splits. Relationships with the dichotomous criterion are then expressed as a percentage, using the calculation $50 \%$ $\pm r / 2$. Therefore, we classified students into positive and negative patterns: A positive pattern represented high learning motivation and high hardiness, and a negative pattern denoted low learning motivation and low hardiness. Compared with students exhibiting a negative pattern, students with a positive pattern were $32 \%$ more likely to remain motivated at the end of the academic term. In addition, they were also $23 \%$ less likely to be depressed and $24 \%$ more likely to react positively to the class.

\section{GENERAL DISCUSSION}

Our primary purpose in this study was to examine psychological hardiness sentiments within an educational context. To our knowledge, this is one of the first studies to jointly examine learning motivation sentiments and psychological hardiness relationships with individuals' attitude toward motivated learning, depressive affect, and reactions to the learning experience.

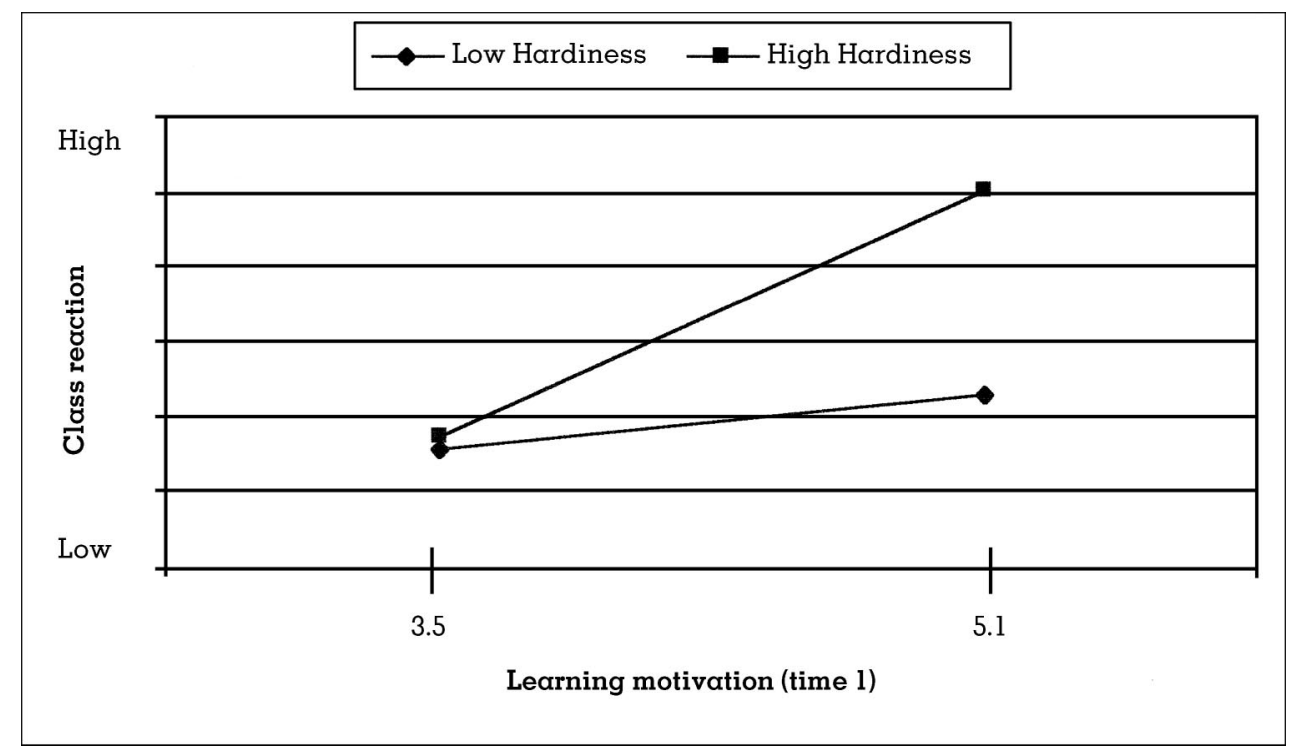

FIGURE 3

Reactions to the class predicted by the two-way interaction between learning motivation (Time 1) and school-related psychological hardiness at low and high levels of hardiness. The numbers 3.5 and 5.1 are one standard deviation above and below the mean (4.3) for the learning motivation (Time 1) scale. 


\section{Review of Hypotheses and Suggestions for Future Research}

It is important to note that the significant interactions explained incremental variance in the criteria beyond various controls accounting for a large proportion of variance. For instance, students' desirable responding was strongly related with depressive symptoms $(\beta=-.30, p<.001)$ suggesting students may have been less than honest with regard to experiencing depressive episodes. Furthermore, dispositional learning orientations accounted for, on average, $17 \%$ of the variance. Consequently, with an average $26 \%$ of the criterion variance explained by control variables, our tests are a conservative estimate of the true relationships.

As predicted in Hypothesis 1, the moderated regression results suggested the joint consideration of students' initial learning motivation and hardiness interact to influence postlearning motivation. As hypothesized, the two-way interaction was related with motivation to learn at Time 2, even after the controls and main effects accounted for $50 \%$ of the variance. Referring back to Figure 1, it appears that although hardiness had minimal effects under low-motivation conditions, it generally had a stronger influence under high-motivation conditions. This result is consistent with findings from other studies (cf. Bortone, 1999; Roth et al., 1989; Wiebe, 1991). This finding suggests that students who report having a hardy perspective toward school-related activities may, in fact, have a natural buffer against adverse events such as academic-related time constraints or pressures that may impact class performance. It appears that hardiness helps those with moderate to high initial motivation maintain or even enhance their motivation as the academic term progresses. However, future research is needed to confirm this proposition.

For instance, future research should examine the interactive effect of students' learning motivation and hardiness on reactions to performance feedback. In a recent study, Colquitt and Simmering (1998) reported goal orientation variables moderated individuals' responses to performance feedback, suggesting learning orientations may buffer individuals against negative effects of poor performance. Coupled with the present study, one might hypothesize that after receiving performance feedback (e.g., poor exam grade), students with hardy dispositions will remain motivated and feel challenged by difficult class material.

Hypothesis 2 predicted the combined impact of being highly motivated and hardy would act as a buffer against acute periods of depression. Students who initially reported being motivated and hardy reported having fewer depressive thoughts (e.g., low self-worth, feeling sad, or discouraged) than all other students who participated in the study. Of interest is that unmotivated/hardy students had the greatest symptoms of depression. Specifically, hardiness interacted with learning motivation to increase depression for students with low initial motivation and decreased depression for those with high initial motivation. This finding was unexpected and is worthy of more discussion.

We originally expected that students with a hardy disposition would be less likely to experience depression. However, as previously discussed and shown in Figure 2, unmotivated/hardy students reported experiencing the most depressive symptoms. We believe these students were experiencing dissonance. These students' hardy attitudes, specifically the commitment and challenge facets, may have conflicted with their lack of motivation to learn the class material. Accordingly, when individuals are subjected to dissonance, they often experience tension and anxiety, which helps to explain why unmotivated/hordy students expressed more depressive feelings. Thus, we believe students were struggling with their dispositional inclination to be positive, committed, and enjoy any challenge while simultaneously experiencing difficulties (reason unknown) in being motivated to exert the effort needed to learn the Principles of Management class material. In addition, given that the depressive symptoms were assessed at the end of the academic term, it may have been that the optimism associated with high hardiness was no longer germane to academic success and therefore unable to overcome the depression associated with low motivation.

In terms of future research, an important question is this: Are these findings specific to the management class sampled in the study, or do students' motivation and hardy constructs, when combined, have similar depressive effects in other classes or contexts? At the very least, future research that monitors a sample of students while collecting subjective (e.g., depression, class reaction) and objective (exam grades, absences, dropping a class) criteria in multiple classes is needed. Furthermore, we encourage future researchers to collect qualitative data from student participants. Simultaneous verbal protocol (Svenson, 1979) is a method that involves having subjects verbalize their thoughts while completing a task. These selfreported explanations of thought and decision- 
making processes (e.g., persistence in studying, effort expended on assignments) may yield a deeper understanding of the students' judgments, and, therefore, provide a better understanding of this study's findings.

With regard to Hypothesis 3, students who reported being motivated and psychologically hardy at the beginning of the academic term also rated their class experience more positively than other students. Hardy students (when unmotivated) responded similarly to motivated, yet nonhardy students as well as the unmotivated/nonhardy students. From a didactic viewpoint, these findings are particularly interesting. At the end of the academic term, motivated/hardy individuals felt more aware and competent in the use of the skills learned, whereas the remaining students felt to a lesser extent comfortable with the skills taught. Although objective performance measures were not available in our study due to anonymity concerns, the next logical step in this line of research is to collect performance measures in an attempt to validate the sentiments reported here.

With regard to instructor evaluations, the results indicated no relationships with the learning motivation and hardiness interaction. We thought that students' motivation might interact with hardy persons' optimistic outlook to inflate instructor evaluations in a positive manner. The finding that the interaction did not account for any variance in instructor evaluations beyond the main effects was surprising. Again, this may be the result of giving the evaluations at the end of the term when the optimism associated with hardiness is less germane to the issue, and, therefore, less likely to inflate the assessments beyond the main effect of a generally positive attitude toward the class. It would be interesting for future researchers to test for an interaction on instructor assessment conducted at earlier times during the term.

\section{Implications for Educational Practice}

The results of this study are not only of theoretical importance but also have important practical implications for educators and student self-development. Our results suggest that both initial learning motivation and hardiness make unique contributions to the maintenance of classroom motivation, depressive symptoms, and post hoc evaluations of the class experience. In addition, our results suggest that motivation and hardiness often interact to magnify the implications of these main effects.

What can be done to help students maintain or enhance motivation, reduce the likelihood they will experience periods of acute depression, and help them have a more positive educational experience? Our results suggest that first, the early development of high learning motivation is critical. All interactions suggest that hardiness amplifies the basic positive effects of high initial learning motivation. In fact, as shown in Figures 1 and 3, hardiness has no discernible effects on Time 2 learning motivation or class reactions if initial learning motivation is low. More crucially, as shown in Figure 2, hardiness magnifies depression if learning motivation is low. Therefore, we suggest educators and students must first focus on building learning motivation for education in general as well as for specific classes.

The literature on motivation-to-learn provides many examples and descriptions of how learning motivation can be enhanced (e.g., Ford, 1997; Noe, 1999). In short, educators can enhance learning motivation by emphasizing the importance and applicability of the material and by trying to connect the material to students' intrinsic motives. As part of freshmen orientation sessions, for example, educational institutions could provide students opportunities to learn more about their dispositions using self-assessments (e.g., Myers-Briggs Inventory) and help them find fields of study (e.g., Holland's Vocational Preferences Inventory) that fit their intrinsic interests. Learning motivation is likely to be greater if a student feels a particular class is consistent with their interests and with personally satisfying career goals. Moreover, we suggest institutions provide students with a strong grounding in self-awareness and offer guidance and choice in class selection. Any one suggestion should help create conditions likely to encourage high learning motivation sentiments.

Building off a base of high initial motivation, efforts to increase students' hardiness can pay off in sustained motivation, lower depression, and more positive evaluations of the educational experience. The research on hardiness clearly suggests that it is an orientation that can be developed and enhanced. Although it may be possible for a particular instructor to improve students' hardiness, because their contact is limited, it is more likely that longer term institutionalized support and effort will be required. Given that opportunities to improve students' hardiness may be few and for between, instructors con help students by linking them to counseling resources using "hot links" on the class Websites. In addition, nonstigmatized academic counseling, tutoring, support groups, and specific days off (e.g., "dead days") during stressful periods all contribute to a low stress environment. Institutions can also provide hardiness training.

In as little as 15 hours over 10 sessions, Maddi et 
al. (1998) found that hardiness training had beneficial effects on participants' hardiness and job satisfaction, coupled with decreases in subjective strain and illness severity. Although the AACSB and counseling services at the university where this data was collected could not provide data regarding the prevalence of stress management training for students, we cannot foresee any reasons why such training could not be conducted. If brief training sessions proved successful in college or university settings, the potential benefits for students could far outweigh any administrative costs incurred. The office for student services or counseling services could coordinate the testing, feedback, and training sessions. The training could take place during freshman orientations or in an early class required of all students.

With technological advancements, many universities are beginning to offer e-classes (also referred to as e-learning or distance-based learning) to students. Consequently, the Web could be used as the delivery method, including the administration and automatic scoring of the hardiness inventory. Offering students an increased sense of anonymity, the Internet has several benefits over traditional instruction methods, and, therefore, we suggest universities take advantage and develop hardiness training modules that are required of all students.

For those instructors or administrators who wish to develop hardiness training modules, the following summarizes Maddi et al.'s (1998) four-part training program. The introductory port is comprised of two sessions. During these, participants describe their stressful conditions and the trainer describes the purpose of the various class sessions. In sessions three through six, participants practice three techniques for transformational coping (Maddi, 1987). These include: (a) broadening participants' viewpoints to deepen their understanding of the stressor, (b) exploring bodily sensations for personal and emotional insight, and (c) teaching participants to learn to accept unchangeable situations without becoming resentful or feeling sorry for oneself. During sessions seven through nine, participants develop and carry out action plans for changing stressful circumstances. Additionally, trainers provide developmental feedback to reinforce participants' commitment, control, and challenge. The final session encourages persons to continue using the approach as stressful circumstances occur.

Recent studies have clearly shown depression among college students is a prevalent problem (e.g., Furr et al., 2001), with a subgroup of students' depressed mood developing into a depressive syn- drome that includes symptoms other than an unhappy mood, most notably levels of anxiety (Compas et al., 1993). Brackney and Karabenick (1995) reported, for example, students' depression had a significant indirect effect on academic performance via motivation and learning strategies. Although past research has extensively examined motivation to learn (e.g., Colquitt et al., 2000) and self-regulated learning (Pintrich \& De Groot, 1990), hardiness attitudes have not been included in past educational research. This study's findings suggest that if students' learning motivation and hardiness levels are positively influenced, psychological well-being might also be positively affected (e.g., Maddi, 1987; Maddi et al., 1998). Expressed in terms of a binomial effect size display, motivated/ hardy students were $23 \%$ less likely to experience depression, defined as a negative emotional tone. Thus, the office for student affairs or university counseling services should assess students' learning motivation and hardiness levels and offer support to those needing it. Using Web-based technology, students' assessment could be accomplished using the learning motivation and school-related hardiness measures and training modules developed based on the work of Maddi et al.

Educators also need to be proactive (rather than reactive) and take additional steps to prevent stressors and student depression. For example, if grade pressures are extreme for some academic majors, environmental assessments should be developed, and faculty within those departments may need to be better trained at recognizing and responding to students who are in need of help. Departments might also ask their university's counseling center for assistance in developing workshops used to strengthen students' abilities to cope with the increasing academic demands. Unfortunately, less than $20 \%$ of students who have reported experiencing depression indicated that they had sought help (Furr et al., 2001). In part, the lack of help-seeking behavior by students could be explained by the negative stigma associated with persons who seek counseling (this stigma is expected to have an even more dramatic effect on college students). Because most students have access to computer networks and more faculty are providing class Web sites, instructors are encouraged to provide Web links to university services and outside Web sites designed to address students' questions. Additional alternatives might include faculty slowing the pace of learning when dealing with difficult course material, providing incentives to increase students' learning motivation, or providing students with options concerning coursework deliverables. Perhaps even educating 
students on college resources available to them, for example, as part of covering course syllabi, might enhance hardiness by empowering the students to take control.

\section{Study Limitations}

Despite its contributions, this study is not without certain methodological limitations. The most significant of these is that certain measures, for example, students' grades, were not collected as part of the study. In addition, the number and nature of particular stressors and the level of strain encountered (or perceived) by students is not actually known. For example, achieving both very high and very low grades proceeding into the final exam week could induce stress. Therefore, it is possible that factors other than those measures collected might explain our findings here. Although we are unable to rule out this latter explanation, the development of hypotheses by way of a significant and empirically supported theory helps to alleviate our concern. Future researchers should, however, collect additional variables including students' grades and depression scores early in the academic term.

Another potential limitation in the study concerns the use of self-report questionnaires. Because the variables were attitudinal, it was essential to assess students' perceptions directly. More importantly, the 2-month period between administration of the surveys and the way we separated our assessments of predictors and criteria should reduce some common method variance concerns (Podsakoff \& Organ, 1986). Furthermore, the statistically significant interactions were obtained only after numerous controls and main effects (and potential sources of common method variance) were entered into the regression models. To the extent that any common method bias was associated with any of these variables, it would have been diminished in terms of influence on the two-way crossproduct terms entered last in the regression equations. However, future research collecting data not relying on self-report would be desirable. Researchers could conduct longitudinal studies whereby students are followed (and periodically assessed) during their years as a student. In addition, parents, siblings attending same school, spouses or significant others, and peers could all be asked to provide judgments to determine if individuals are experiencing psychological and physiological symptoms related to increased strain.

In conclusion, despite the statistical significance of the control and main effect variables, the data provided support for the interaction hypotheses. These findings illustrate the importance of considering the joint impact of learning motivation and hardiness when assessing posttraining attitudes and reactions. Given the fact that our work here is the first to speculate on hardiness' moderating influence on individuals' pre-classroom attitudes and its impact on post-class attitudes and reactions, our results provide direction for educational researchers and practitioners.

\section{REFERENCES}

Aiken, L. S., \& West, S. G. 1991. Multiple regression: Testing and interpreting interactions. Newbury Park, CA: Sage.

Alliger, G. M., Tannenbaum, S. I., Bennett, W., Traver, H., \& Shotland, A. 1997. A meta-analysis of the relations among training criteria. Personnel Psychology, 50: 341-358.

American Psychiatric Association. 1994. Diagnostic and statistical manual of mental disorders (4th ed.). Washington, DC: Author.

Antonovsky, A. 1979. Health, stress, and coping. San Francisco, CA: Jossey-Bass.

Baldwin, T. T., Magjuka, R. J., \& Loher, B. T. 1991. The perils of participation: Effects of choice of training on trainee motivation and learning. Personnel Psychology, 44: 51-65.

Bartone, P. T. 1999. Hardiness protects against war-related stress in Army Reserve forces. Consulting Psychology Journal: Practice and Research, 51: 72-82.

Bartone, P. T., Ursano, R. J., Wright, K. M., \& Ingraham, L. H. 1989. The impact of a military disaster on the health of assistance workers. The Journal of Nervous and Mental Disease, 177: 317-328.

Brackney, B. E., \& Karabenick, S. A. 1995. Psychopathology and academic performance: The role of motivation and learning strategies. Journal of Counseling Psychology, 42: 456-465.

Britt, T. W., Adler, A. B., \& Bartone, P. T. 2001. Deriving benefits from stressful events: The role of engagement in meaningful work and hardiness. Journal of Occupational Health Psychology, 6: 53-63.

Button, S. B., Mathieu, J. E., \& Zajac, D. M. 1996. Goal orientation in organizational research: A conceptual and empirical foundation. Organizational Behavior and Human Decision Processes, 67: 26-48.

Campbell, J. P. 1989. An agenda for theory and research. In I. L. Goldstein (Ed.), Training and development in organizations: 469-486. San Francisco, CA: Jossey-Bass.

Carver, C. S. 1989. How should multifaceted personality constructs be tested? Issues illustrated by self-monitoring, attributional style, and hardiness. Journal of Personality \& Social Psychology, 56: 577-585.

Cervone, D., Kopp, D. A., Schaumann, L., \& Scott, W. D. 1994. Mood, self-efficacy, and performance standards: Lower moods induce higher standards for performance. Journal of Personality and Social Psychology, 67: 499-512.

Chemers, M. M., Hu, L., \& Garcia, B. F. 2001. Academic selfefficacy and first-year college student performance and adjustment. Journal of Educational Psychology, 93: 55-64.

Cohen, J., \& Cohen, P. 1983. Applied multiple regression/corre- 
lation analysis for the behavioral sciences. Hillsdale, NJ: Erlbaum.

Colquitt, J. A., LePine, J. A., \& Noe, R. A. 2000. Toward an integrative theory of training motivation: A meta-analytic path analysis of 20 years of research. Journal of Applied Psychology, 85: 678-707.

Colquitt, J. A., \& Simmering, M. J. 1998. Conscientiousness, goal orientation, and motivation to learn during the learning process: A longitudinal study. Journal of Applied Psychology, 83: 654-665.

Compas, B. E., Ey, S., \& Grant, K. E. 1993. Taxonomy, assessment, and diagnosis of depression during adolescence. Psychological Bulletin, 114: 323-344.

Cordes, C. L., \& Doughtery, T. W. 1993. A review and an integration of research in job burnout. Academy of Management Review, 18: 621-656.

Costa, P. T., Jr., \& McCrae, R. R. 1992. The revised NEO personality inventory NEO-PI-R and NEO five-factor inventory NEO-FFI professional manual. Odessa, FL: Psychological Assessment Resources.

Dobson, K. S., \& Kendall, P. C. 1993. Psychopathology and cognition. San Diego, CA: Academic Press.

Dweck, C. S., \& Leggett, W. L. 1988. A social-cognitive approach to motivation and personality. Psychological Review, 95: 256-273.

Dykman, B. M. 1998. Integrating cognitive and motivational factors in depression: Initial tests of a goal-orientation approach. Journal of Personality and Social Psychology, 74: 139-158.

Farr, J. L., \& Middlebrooks, C. L. 1990. Enhancing motivation to participate in professional development. In S. L. Willis, \& S. S. Dubin (Eds.), Maintaining professional competence: San Francisco, CA: Jossey-Bass.

Fisher, T. 1998. High anxiety: Preparing trainees to learn. Training and Development, 52: 14-15.

Florian, V., Mikulincer, M., \& Taubman, O. 1995. Does hardiness contribute to mental health during a stressful real-life situation? The roles of appraisal and coping. Journal of Personality and Social Psychology, 68: 687-695.

Fogarty, G. J., Machin, M. A., Albion, M. J., Sutherland, L. F., Lalor, G. I., \& Revitt, S. 1999. Predicting occupational strain and job satisfaction: The role of stress, coping, personality, and affectivity variables. Journal of Vocational Behavior, 54: $429-452$.

Ford, J. K. 1997. Improving training effectiveness in work organizations. Mahwah, NJ: Erlbaum.

Funk, S. C., \& Houston, B. K. 1987. A critical analysis of the hardiness scales' validity and utility. Journal of Personality and Social Psychology, 53: 572-578.

Furr, S. R., Westefeld, J. S., McConnell, G. N., \& Jenkins, J. M. 2001. Suicide and depression among college students: $A$ decade later. Professional Psychology: Research \& Practice, 32: 97-100.

Gelso, C. J., \& Fassinger, R. E. 1992. Personality, development, and counseling psychology: Depth, ambivalence, and actualization. Journal of Counseling Psychology, 39: 275-298.

Goldstein, L. L. 1993. Training in organizations: Needs assessment, development, and evaluation (3rd ed.). Monterey, CA: Brooks/Cole.

Greller, M., \& Parsons, C. K. 1988. Psychosomatic complaints scale of stress: Measure development and psychometric properties. Educational and Psychological Measurement, 48: 1051-1065.

Hinkin, T. R. 1995. A review of scale development in the study of behavior in organizations. Journal of Management, 21: 967988.

Hinkin, T. R. 1998. A brief tutorial on the development of measures used for use in survey questions. Organizational Research Methods, 1: 104-121.

Hull, J. G., Lehn, D. A., \& Tedlie, J. C. 1991. A general approach to testing multifaceted personality constructs. Journal of Personality and Social Psychology, 61: 932-945.

Hull, J. G., Van Treuren, R. R., \& Virnelli, S. 1987. Hardiness and health: A critique and alternative approach. Journal of Personality and Social Psychology, 53: 518-530.

Kobasa, S. C. 1979. Stressful life events, personality and health: An inquiry into hardiness. Journal of Personality and Social Psychology, 37: 1-11.

Kobasa, S. C. 1982. The hardy personality: Toward a social psychology of stress and health. In J. Suls, \& G. Sanders (Eds.), The social psychology of health and illness. Hillsdale, NJ: Erlbaum.

Kobasa, S. C., Maddi, S. R., \& Courington, S. 1981. Personality and constitution as mediators in the stress-illness relationship. Journal of Health and Social Behavior, 22: 368-378.

Kobasa, S. C., Maddi, S. R., \& Kahn, S. 1982. Hardiness and health: A prospective study. Journal of Personality and Social Psychology, 42: 168-177.

Kobasa, S. C., Maddi, S. R., Puccetti, M. C., \& Zola, M. A. 1985. Effectiveness of hardiness, exercise, and social support as resources against illness. Journal of Psychosomatic Research, 29: 525-533.

Kobasa, S. C., \& Puccetti, M. C. 1983. Personality and social resources in stress resistance. Journal of Personality and Social Psychology, 45: 839-850.

Krosnick, J. A. 1999. Survey research. Annual Review of Psychology, 50: 537-567.

Lazarus, R. S., \& Folkman, S. 1984. Stress, appraisal, and coping. New York: Springer.

Macan, T. H., Shahani, C., Dipboye, R. L., \& Phillips, A. P. 1990. College students' time management correlations with academic performance and stress. Journal of Educational Psychology, 82: 760-768.

Maddi, S. R. 1987. Hardiness training at Illinois Bell Telephone. In J. Opatz (Ed.), Health promotion evaluation: 101-115. Stephens Point, WI: National Wellness Institute.

Maddi, S. R. 1999a. Comments on trends in hardiness research and theorizing. Consulting Psychology Journal: Practice \& Research, 51: 67-71.

Maddi, S. R. 1999b. The personality construct of hardiness: I. Effects on experiencing, coping, and strain. Consulting Psychology Journal: Practice \& Research, 51: 83-94.

Maddi, S. R., \& Hightower, M. 1999. Hardiness and optimism as expressed in coping patterns. Consulting Psychology Journal: Practice and Research, 51: 95-105.

Maddi, S. R., \& Kobasa, S. C. 1984. The hardy executive: Health under stress. Homewood, IL: Dow Jones-Irwin. 
Maddi, S. R., Kahn, S., \& Maddi, K. L. 1998. The effectiveness of hardiness training. Consulting Psychology Journal: Practice \& Research, 50: 78-86.

Martocchio, J. J., \& Webster, J. 1992. Effects of feedback and cognitive playfulness on performance in microcomputer training. Personnel Psychology, 45: 553-578.

Mathieu, J. E., \& Martineau, J. W. 1997. Individual and situational influences in training motivation. In J. K. Ford, S. W. J. Kozlowski, K. Kraiger, E. Salas, \& M. S. Teachout (Eds.), Improving training effectiveness in work organizations: 193-222. Hillsdale, NJ: Erlbaum.

Mathieu, J. E., Tannenbaum, S. I., \& Salas, E. 1992. Influences of individual and situational characteristics on measures of training effectiveness. Academy of Management Journal, 35: $828-847$.

Noe, R. A. 1986. Trainees' attributes and attitudes: Neglected influences on training effectiveness. Academy of Management Review, 11: 736-749.

Noe, R. A. 1999. Employee training and development. Boston, MA: Irwin McGraw-Hill.

Noe, R. A., \& Schmitt, N. 1986. The influence of trainee attitudes on training effectiveness: Test of a model. Personnel Psychology, 39: 497-523.

Noe, R. A., Wilk, S. L., Mullen, E. J., \& Wanek, J. E. 1997. Employee development: Construct validation issues. In J. K. Ford, S. W. J. Kozlowski, K. Kraiger, E. Salas, \& M. S. Teachout (Eds.), Improving training effectiveness in work organizations: 153-189. Mahwah, NJ: Erlbaum.

Ones, D. S., Viswesvaran, C., \& Reiss, A. D. 1996. Role of social desirability in personality testing for personnel selection: The red herring. Journal of Applied Psychology, 6: 660-679.

Paulhus, D. L. 1991. Measurement and control of response bias. In J. P. Robinson, P. R. Shaver, \& L. S. Wrightsman (Eds.), Measures of personality and social psychological attitudes: 17-59. San Diego, CA: Academic Press.

Pintrich, P. R., \& De Groot, E. V. 1990. Motivational and selfregulated learning components of classroom academic performance. Journal of Educational Psychology, 82: 33-40.

Podsakoff, P. M., \& Organ, D. W. 1986. Self-reports in organizational research: Problems and prospects. Journal of Management, 12: 531-544.

Rhonewalt, F., \& Agustsdottir, S. 1984. On the relationship of hardiness to the Type A behavior pattern: Perception of life events versus coping with life events. Journal of Research in Personality, 18: 212-223.

Rhonewalt, F., \& Zone, J. B. 1989. Appraisal of life change, depression, and illness in hardy and nonhardy women. Journal of Personality and Social Psychology, 56: 81-88.

Rosenthal, R. 1991. Meta-analytic procedures for social research. Newbury Park, CA: Sage Publications.

Rosenthal, R., \& Rosnow, R. L. 1984. Essentials of behavioral research: Methods and data analysis. New York: McGrawHill.

Rosnow, R. L., \& Rosenthal, R. 1996. Computing contrasts, effect sizes, and counternulls on other people's published data: General procedures for research consumers. Psychological Methods, 1: 331-340.

Roth, D. L., Wiebe, D. J., Fillingim, R. B., \& Shay, K. A. 1989. Life events, fitness, hardiness, and health: A simultaneous analysis of proposed stress-resistance effects. Journal of Personality and Social Psychology, 57: 136-142.

Sansone, C., \& Harackiewicz, J. M. 1996. "I don't feel like it": The function of interest in self-regulation. In L. L. Martin, \& A. Tesser (Eds.), Striving and feeling: Interactions among goals, affect, and self-regulation: 203-228. Mahwah, NJ: Erlbaum.

Sansone, C., Wiebe, D. J., \& Morgan, C. 1999. Self-regulating interest: The moderating role of hardiness and conscientiousness. Journal of Personality, 67: 701-733.

Scheier, M. F., Carver, C. S., \& Bridges, M. W. 2000. Optimism, pessimism, and psychological well-being. In E. C. Chang (Ed.), Optimism and pessimism: Implications for theory, research, and practice: 189-216. Washington, DC: American Psychological Association.

Shepperd, J. A., \& Kashani, J. H. 1991. The relationship of hardiness, gender, and stress to health outcomes in adolescents. Journal of Personality, 59: 747-768.

Staw, B. M., Sutton, R. I., \& Pelled, L. H. 1994. Employee positive emotion and favorable outcomes at the workplace. Organization Science, 5: 51-71.

Svenson, O. 1979. Process descriptions of decision making. Organizational Behavior and Human Performance, 23: 86-112.

Swick, K. J. 1987. Student stress: A classroom management system. Washington, DC: National Education Association.

Tannenbaum, S. I., \& Yukl, G. 1992. Training and development in work organizations. Annual Review of Psychology, 43: 399441.

Tellegen, A. 1985. Structure of mood and personality and their relevance to assessing anxiety, with an emphasis on selfreport. In A. H. Tuma, \& J. D. Maser (Eds.), Anxiety and the anxiety disorders: 681-706. Hillsdale, NJ: Erlbaum.

Thurstone, L. L. 1947. Multiple-factor analysis. Chicago: University of Chicago Press.

Tomaka, J., \& Blascovich, J. 1994. Effects of justice beliefs on cognitive appraisal of and subjective physiological, and behavioral responses to potential stress. Journal of Personality and Social Psychology, 67: 732-740.

Tomaka, J., Blascovich, J., Kelsey, R. M., \& Leitten, C. L. 1993. Subjective, physiological, and behavioral effects of threat and challenge appraisal. Journal of Personality and Social Psychology, 65: 248-260.

Tomaka, J., Blascovich, J., Kibler, J., \& Ernst, J. M. 1997. Cognitive and physiological antecedents of threat and challenge appraisal. Journal of Personality and Social Psychology, 73: 63-72.

VandeWalle, D. M. 1997. Development and validation of a work domain goal orientation instrument. Educational and Psychological Measurement, 57: 995-1015.

Watson, D., \& Clark, L. A. 1984. Negative affectivity: The disposition to experience aversive emotional states. Psychological Bulletin, 96: 465-490.

Watson, D., Clark, L. A., \& Tellegen, A. 1988. Development and validation of brief measures of positive and negative affect: The PANAS scales. Journal of Applied Psychology, 54: 10631070.

Weiten, W., Lloyd, M. A., \& Lashley, R. L. 1991. Psychology applied to modern life: Adjustment in the 90s. Pacific Grove, CA: Brook \& Cole Publishing. 
Westefeld, J. S., \& Furr, S. R. 1987. Suicide and depression among college students. Professional Psychology: Research and Practice, 18: 119-123.

Westman, M. 1990. The relationship between stress and performance: The moderating effect of hardiness. Human Performance, 3: 141-155.

Wexley, K. N., \& Baldwin, T. T. 1986. Posttraining strategies for facilitating positive transfer: An empirical exploration. Academy of Management Journal, 29: 503-520.
Wiebe, D. J. 1991. Hardiness and stress moderation: A test of proposed mechanisms. Journal of Personality \& Social Psychology, 60: 89-99.

Wiebe, D. J., \& McCallum, D. M. 1986. Health practices and hardiness as mediators in the stress-illness relationship. Health Psychology, 5: 425-438.

Zirkel, S., \& Cantor, N. 1990. Personal construal of life tasks: Those who struggle for independence. Journal of Personality \& Social Psychology, 58: 172-185.

Michael S. Cole is a senior research fellow and lecturer at the Institute for Leadership and Human Resource Management at the University of St. Gallen in Switzerland. His research interests include recruitment and staffing, individual's psychological well-being, and emotions. Cole received his $\mathrm{PhD}$ from Auburn University.

Hubert S. Feild is Torchmark Professor of Management in the Department of Management at Auburn University. His interests include human resource selection and research methods. Feild holds a PhD in industrial psychology from the University of Georgia.

Stanley G. Harris is the Celita Everett Professor of Management and director of the Physicians Executive MBA Program at Auburn University. His research interests include change management, sense making, and emotions. He received his $\mathrm{PhD}$ in organizational psychology from the University of Michigan.

\section{APPENDIX A \\ Exploratory Factor Analysis Results}

\begin{tabular}{|c|c|c|c|c|}
\hline \multirow[b]{2}{*}{ School-Related Hardiness Items } & \multicolumn{4}{|c|}{ Factor } \\
\hline & I & II & III & IV \\
\hline 12. Most days, school is really interesting to me. & .82 & & & \\
\hline 16. I really look forward to most things at school. & .80 & & & \\
\hline 2. I often wake up eager to get back to my school work. & .73 & & & \\
\hline $\begin{array}{l}\text { 1. Most of my school-related activities and assignments are } \\
\text { worthwhile. }\end{array}$ & .57 & .45 & & \\
\hline 5. Most people can be taught to be a good student. & .42 & & & \\
\hline 10. Trying your best at academic work really pays off in the end. & & .80 & & \\
\hline 18. I can usually improve my academic performance by trying harder. & & .78 & & \\
\hline 3. I can achieve my academic goals by working hard. & & .77 & & \\
\hline $\begin{array}{l}\text { 8. When I make a mistake in school, I can usually correct them on my } \\
\text { own. }\end{array}$ & & & & -.74 \\
\hline $\begin{array}{l}\text { 13. When I'm working on a difficult assignment, I know when to seek } \\
\text { help. }\end{array}$ & & & & -.62 \\
\hline 15. I am in control of most things that happen to me at school. & & .44 & & -.60 \\
\hline
\end{tabular}

Note. $N=348$ 
Copyright of Academy of Management Learning \& Education is the property of Academy of Management and its content may not be copied or emailed to multiple sites or posted to a listserv without the copyright holder's express written permission. However, users may print, download, or email articles for individual use. 